\title{
Short-term consumption of a plant protein diet does not improve glucose homeostasis of young C57BL/6J mice
}

\author{
Dudley W. Lamming ${ }^{a, b, *}$, Emma L. Baar ${ }^{a, b}$, Sebastian I. Arriola Apelo ${ }^{a, b, c}$, Valeria Tosti ${ }^{\mathrm{d}}$ \\ and Luigi Fontana ${ }^{\mathrm{d}, \mathrm{e}, \mathrm{f}, *}$ \\ ${ }^{a}$ Department of Medicine, University of Wisconsin-Madison, Madison, WI, USA \\ ${ }^{\mathrm{b}}$ William S. Middleton Memorial Veterans Hospital, Madison, WI, USA \\ ${ }^{\mathrm{c}}$ Department of Dairy Science, University of Wisconsin-Madison, Madison, WI, USA \\ ${ }^{\mathrm{d}}$ Department of Medicine, Washington University in St. Louis, MO, USA \\ ${ }^{\mathrm{e}}$ Department of Clinical and Experimental Science, Brescia University, Brescia, Italy \\ ${ }^{\mathrm{f}}$ CEINGE Biotecnologie Avanzate, Napoli, Italy
}

\begin{abstract}
Recently, it has become apparent that dietary macronutrient composition has a profound impact on metabolism, health and even lifespan. Work from many laboratories now suggest that dietary protein quality - the precise amino acid composition of the diet, as well as possibly the source of dietary protein - may also be critical in regulating the impact of diet on health. Perhaps in part due to the naturally low methionine content of plants, vegan diets are associated with a decreased risk of diabetes and improved insulin sensitivity, but this association is confounded by the lower overall protein intake of vegans. Here, we test the effect of consuming isocaloric rodent diets with similar amino acid profiles derived from either plant protein or dairy protein. We find that male C57BL/6J mice consuming either diet have similar glycemic control, as assessed by glucose, insulin, and pyruvate tolerance tests, and have similar overall body composition. We conclude that short-term feeding of plant protein has no positive or negative effect on the metabolic health of young male C57BL/6J mice, and suggest that dietary interventions that alter either dietary protein levels or the levels of specific essential amino acids are more likely to improve metabolic health than alterations in dietary protein source.
\end{abstract}

Keywords: Plant protein, dairy protein, mice, macronutrient composition, glucose tolerance, insulin sensitivity

\section{Introduction}

As obesity and diabetes become increasingly prevalent around the world, the popularity of dietary strategies to lose weight and regain metabolic health has boomed. Dietary strategies that seek to restrict caloric intake are notoriously unsuccessful, due to

\footnotetext{
${ }^{*}$ Corresponding author: Dudley W. Lamming, William S. Middleton Memorial Veterans Hospital, 2500 Overlook Terrace, Room C3127 Research 151, Madison, WI 53705, USA. Tel.: +1608 2561901 x12861; Fax: +1 608263 9983; E-mail: dlamming@medicine.wisc.edu and Luigi Fontana, Division of Geriatrics and Nutritional Science, Washington University, School of Medicine, 4566 Scott Avenue, Campus Box 8113, St. Louis, MO 63110, USA. Tel.: +1 314747 1485; Fax: +1 314362 7657; E-mail:1fontana@wustl.edu.
}

both poor long-term compliance and compensatory changes in the metabolism of the dieter that inhibit weight loss. As an alternative, so-called "fad" diets based on the concept that not all calories are equivalent have become increasingly popular. These include high-protein, low carbohydrate diets such as the Atkins or the Paleo diets.

Both prospective and randomized clinical trials have demonstrated that contrary to conventional wisdom, low protein diets enhance metabolic health, promoting leanness, lowering fasting blood glucose levels, and leading to decreased risk of developing diabetes in humans $[1,2]$. Studies of humans also suggest that high protein diets are associated with increased risk of cardiovascular disease, cancer and mortality [3, 4]. These results are backed up 
by numerous recent studies demonstrating that consumption of a protein restricted (PR) diet promotes glucose tolerance, insulin sensitivity, and longevity in both rodents and humans $[1,5-8]$.

An unanswered question is how dietary protein source may impact metabolic health. Many health benefits are attributed to plant-based vegetarian or vegan diets [9-11]; however, a complicating issue in these studies is that those consuming a vegetarian or vegan diet may also be consuming less overall dietary protein. Further, vegan diets have reduced levels of the essential amino acid methionine, restriction of which promotes health and longevity in rodents [12-14]. The evidence that metabolic health is differentially impacted by common natural dietary protein sources is mixed. While a number of studies in humans have concluded that there are no clear differences between animal-based and plant-based diets with respect to metabolic health $[15,16]$, other studies suggest that consumption of dairy protein may promote metabolic health [17].

To help resolve this question, we placed C57BL/6J male mice on either a plant protein-based or a dairy protein-based diet with an equivalent percentage of calories derived from protein, and studied the shortterm consequences of these diets on weight, body composition, and control of glucose homeostasis. Here, we find that plant protein-based and dairy protein-based are indistinguishable with respect to these outcomes. We conclude that altering dietary protein source alone, without altering total protein consumption or the specific amino acid composition of the diet, is insufficient to significantly alter metabolic health in a short-term study.

\section{Results}

\subsection{Glucose homeostasis in mice fed dairy or plant-based diets}

We divided 9 week old C57BL/6J male mice from The Jackson Laboratory equivalently by weight into two different treatment groups. These groups were placed on either a $20 \%$ Plant protein-based diet or a $20 \%$ Dairy protein-based diet, as in a previous study these two diets showed differential effects on tumor growth in NSG mice [18]. The precise composition of the diets is provided in Table 1 .

We placed mice on these diets for 3 weeks, which as we have recently shown, is sufficient to see dramatic improvements in glucose homeostasis when mice are placed on low protein or low branched-chain amino acids diets [1]. We then analyzed glucose metabolism by conducting glucose, insulin, and pyruvate tolerance tests (Fig. 1A-1C). Mice consuming dairy protein or plant protein based diets had similar glucose tolerance (Fig. 1A). During the insulin tolerance test (Fig. 1B) there was an overall trend $(p=0.11)$ towards increased insulin sensitivity in mice consuming a dairy protein based diet, with a statistically significant difference in blood glucose levels $15 \mathrm{~min}$ utes following insulin administration. There were no significant differences during the pyruvate tolerance test (Fig. 1C).

In order to learn more about the effects of these diets on glucose metabolism, we collected fasting blood after 6 weeks on the diets in order to determine fasting glucose and insulin levels and to calculate HOMA-IR. Dairy protein-fed mice had a trend $(p=0.096)$ towards increased fasting blood glucose levels (Fig. 1D), but fasting insulin levels were similar between plant protein and dairy protein-fed mice (Fig. 1E). We then used the fasted blood glucose and insulin levels to calculate insulin resistance using homeostasis model assessment (HOMA2-IR) [19]. Although HOMA2-IR is derived empirically from human insulin clamp data, it is an equally useful surrogate measure of insulin resistance in mice [20, 21]. We found that mice eating plant protein and dairy protein-based diets had similar HOMA2-IR (Fig. 1F).

\subsection{Feeding and body composition of mice on a low protein diet}

We wished to assess the effect of plant protein vs. dairy protein-based diets on body composition. First, we observed no difference in food intake between mice eating either diet (Fig. 2A). We then assessed weight and body composition over eight weeks using an EchoMRI 3-in-1 body composition analyzer. While we did observe a trend towards increased adiposity in mice consuming a dairy protein-based diet $(p=0.11$ ), we observed no statistically significant differences in weight gain, gain of adipose or lean mass, or change in body composition between the groups (Fig. 2B-D).

\section{Discussion}

There is a great deal of interest in identifying dietary strategies to promote health. In particular, recent studies have demonstrated that "a calorie is 
Table 1

Composition and ingredients of experimental diets

\begin{tabular}{|c|c|c|c|}
\hline & $\begin{array}{l}20 \% \text { plant protein } \\
\text { TD. } 120220\end{array}$ & & $\begin{array}{c}20 \% \text { dairy protein } \\
\text { TD. } 120218\end{array}$ \\
\hline Formula (g/kg) & & Formula $(\mathrm{g} / \mathrm{kg})$ & \\
\hline Wheat gluten & 110 & Casein & 170 \\
\hline Corn gluten $(60 \%)$ & 136 & Lactalbumin & 44 \\
\hline Isolated soy protein & 22 & & \\
\hline Corn starch & 325.4 & Corn starch & 380.1 \\
\hline Maltodextrin & 100 & Maltodextrin & 100 \\
\hline Sucrose & 150 & Sucrose & 150 \\
\hline Corn oil & 32 & Corn oil & 32 \\
\hline Olive oil & 32 & Olive oil & 32 \\
\hline Cellulose & 50 & Cellulose & 50 \\
\hline${ }^{*}$ Mineral Mix, w/o Ca \& P & 13.4 & ${ }^{*}$ Mineral Mix, w/o Ca \& P & 13.4 \\
\hline Calcium phosphate & 12 & Calcium phosphate & 8 \\
\hline Calcium carbonate & 7.0 & Calcium carbonate & 10.3 \\
\hline **Vitamin Mix, Teklad & 10 & **Vitamin Mix, Teklad & 10 \\
\hline Diet composition & & Diet composition & \\
\hline Total energy value (kcal/g) & 3.7 & Total energy value $(\mathrm{kcal} / \mathrm{g})$ & 3.7 \\
\hline Carbohydrate (\% Kcal) & 62.4 & Carbohydrate (\% Kcal) & 63.6 \\
\hline Fat $(\% \mathrm{kcal})$ & 17.6 & Fat $(\% \mathrm{kcal})$ & 16.4 \\
\hline Protein $(\% \mathrm{Kcal})$ & 20.0 & Protein $(\% \mathrm{Kcal})$ & 20.0 \\
\hline Leucine $(\mathrm{g} / \mathrm{kg})$ & 21.2 & Leucine $(\mathrm{g} / \mathrm{kg})$ & 18.7 \\
\hline Isoleucine (g/kg) & 7.9 & Isoleucine $(\mathrm{g} / \mathrm{kg})$ & 10.1 \\
\hline Lysine $(\mathrm{g} / \mathrm{kg})$ & 3.9 & Lysine $(\mathrm{g} / \mathrm{kg})$ & 15.7 \\
\hline Methionine $(\mathrm{g} / \mathrm{kg})$ & 4.1 & Methionine $(\mathrm{g} / \mathrm{kg})$ & 4.9 \\
\hline Cysteine $(\mathrm{g} / \mathrm{kg})$ & 3.0 & Cysteine $(\mathrm{g} / \mathrm{kg})$ & 2.0 \\
\hline Arginine $(\mathrm{g} / \mathrm{kg})$ & 7.8 & Arginine $(\mathrm{g} / \mathrm{kg})$ & 6.7 \\
\hline Phenylalanine $(\mathrm{g} / \mathrm{kg})$ & 10.4 & Phenylalanine $(\mathrm{g} / \mathrm{kg})$ & 8.8 \\
\hline Tyrosine $(\mathrm{g} / \mathrm{kg})$ & 5.0 & Tyrosine $(\mathrm{g} / \mathrm{kg})$ & 9.2 \\
\hline Histidine (g/kg) & 4.2 & Histidine $(\mathrm{g} / \mathrm{kg})$ & 4.9 \\
\hline Threonine (g/kg) & 5.5 & Threonine (g/kg) & 8.4 \\
\hline Tryptophan (g/kg) & 1.6 & Tryptophan $(\mathrm{g} / \mathrm{kg})$ & 2.5 \\
\hline Valine $(\mathrm{g} / \mathrm{kg})$ & 8.7 & Valine $(\mathrm{g} / \mathrm{kg})$ & 11.8 \\
\hline
\end{tabular}

*Mineral Mix, w/o Ca \& P (No. 98057), ${ }^{* *}$ Vitamin Mix, Teklad (40060).

not just a calorie" - instead, metabolism is influenced by macronutrient composition, and in particular, metabolic health can be improved in both mice and humans by a low protein diet $[1,5,7]$. An ongoing controversy in the nutrition field has been the effect of dietary protein source - that is, does protein derived from foods such as dairy have an inherent beneficial or negative impact on health? Here, we examined the effect of dairy protein and plant protein-based diets on the metabolic health of C57BL/6J mice, a model which we and others have previously established shows dramatic improvements in metabolic health following restriction of protein or dietary branchedchain amino acids $[1,5,7]$. We observed essentially no differences in glycemic control between mice fed plant protein or dairy protein-based diets, and very little in the way of changes in body composition.

One caveat of this study is that the diets used here utilize processed proteins from plant and dairy sources, and other compounds found in raw and unprocessed foods (e.g. phytoestrogens) may play a role in the metabolic response to plant-based and dairy-based diets in humans. A second caveat of this study is its short-term nature; in particular, adiposity might have differed significantly between diet groups had we continued the study for a longer period of time. A longer-term and/or larger study will be needed to determine if plant protein-based or dairy protein-based diets have different effects on adipose mass, and if so, the physiological and molecular basis for these effects, which could include altered lipogenesis or changes in energy balance. Differences in the digestibility of dairy protein-based and plant protein-based diets may contribute to these effects, as recent studies have shown the microbiome is very responsive to intestinal nitrogen levels [22]. Levels of corn starch also vary between the diets used here, and could potentially also contribute to changes in adiposity. 
A)

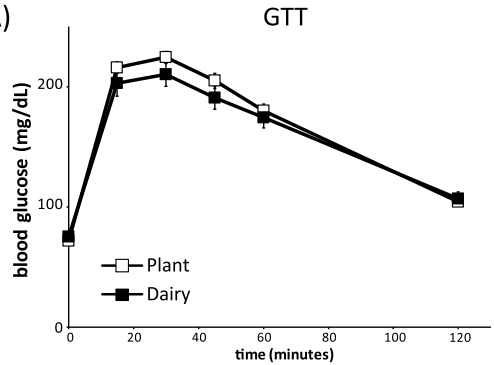

C)

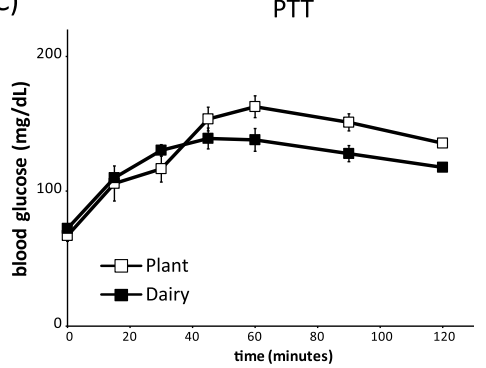

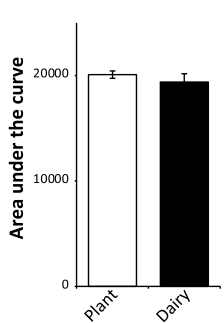

B)

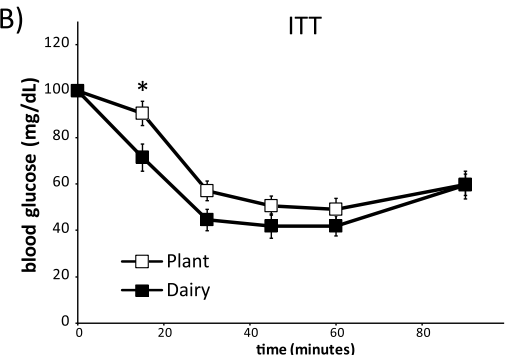

D)

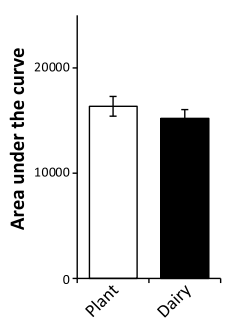

E)

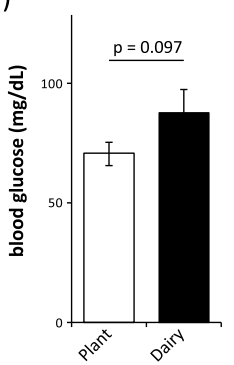

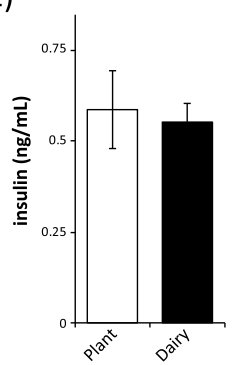

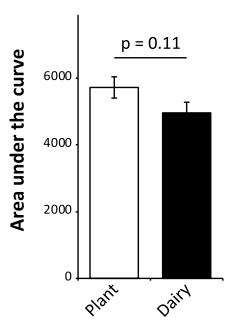

F)

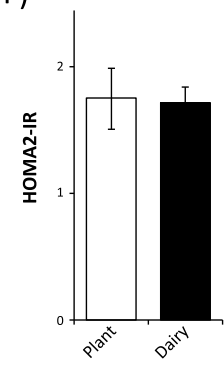

Fig. 1. Mice consuming plant or dairy protein diets have similar control of blood glucose. (A-C) Glucose (A), insulin (B) and pyruvate (C) tolerance tests on male C57BL/6J mice fed a diet based on 20\% Plant protein or 20\% Dairy protein for 3, 4 or 5 weeks, respectively ( $n=9$ /group; Sidak test following repeated-measures ANOVA, ${ }^{*}=p<0.05$ ). Error bars represent SE. (D-F) Mice were fasted overnight and (D) blood glucose and (E) insulin were measured, and (F) the HOMA2-IR was calculated after 6 weeks on the specified diets $(n=9 /$ group; two-tailed $t$-test, $\left.{ }^{*}=p<0.05\right)$. Error bars represent SE.

Importantly, protein quality - the specific amino acid composition of dietary protein - can vary significantly based on the source of dietary protein. Vegan diets in particular may have reduced levels of dietary methionine, which has been linked to health, longevity and insulin sensitivity in mouse and rat studies [12-14, 23-25]. Conversely, meat and dairy are good sources of the three branchedchain amino acids, and a number of rodent studies have linked consumption of BCAAs to glucose intolerance and insulin resistance [1, 26-30]. However, the amino acid composition of the plant protein and dairy protein-based diets used in this study (Table 1) are very similar with respect to both methionine and BCAA content [18]. In conclusion, changing dietary protein source alone is unlikely to be an effective short-term intervention to improve metabolic health; more dramatic changes, which significantly alter dietary protein content or the levels of specific essential amino acids such as methionine, will likely be needed to improve metabolic health.

\subsection{Experimental procedures}

Procedures involving animals were approved by the Institutional Animal Care and Use Committees of the University of Wisconsin-Madison and the William S. Middleton Memorial Veterans Hospital (Madison, WI). Male C57BL/6J mice were purchased from The Jackson Laboratory at 8 weeks of age, and mice were placed on sterilized, irradiated diets prepared by Envigo (formerly Harlan Laboratories), Madison, WI, at 9 weeks of age. The composition and ingredients of each diet are shown in Table 1 [18]. Mice were housed three per cage and were allowed ad libitium access to food and water, and were maintained on a standard 12 hour day/night cycle at approximately $22^{\circ} \mathrm{C}$. Food consumption was measured by measuring the consumption of food over an approximately three day period, and normalizing by the weight of the mice in each cage. Glucose, insulin, and pyruvate tolerance tests were performed by fasting the mice overnight for 16 hours and then injecting either glucose $(1 \mathrm{~g} / \mathrm{kg})$, insulin $(0.75 \mathrm{U} / \mathrm{kg})$, or pyruvate $(2 \mathrm{~g} / \mathrm{kg})$ intraperitoneally. Glucose measurements were taken using a Bayer Contour blood glucose meter and test strips. Mouse body composition was determined using an EchoMRI 3-in-1 Body Composition Analyzer according to the manufacturer's procedures. Insulin levels were determined by ELISA (Crystal Chem). Statistical analysis was performed using Graphpad Prism. 
A)

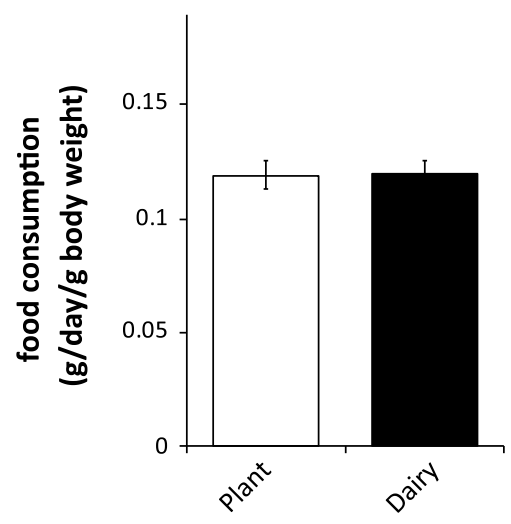

C)

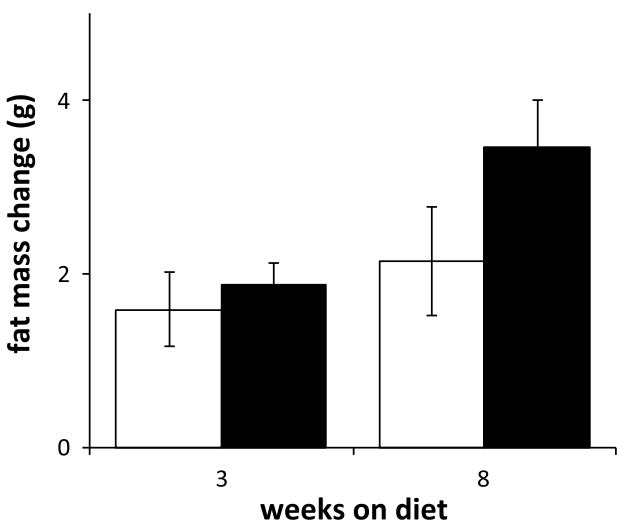

D)

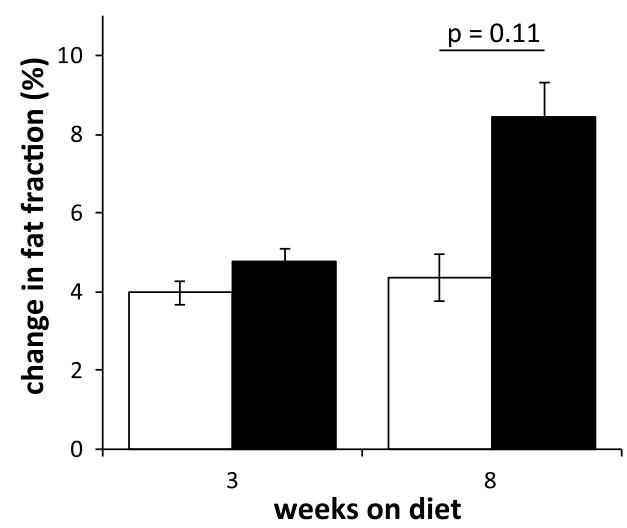

B)

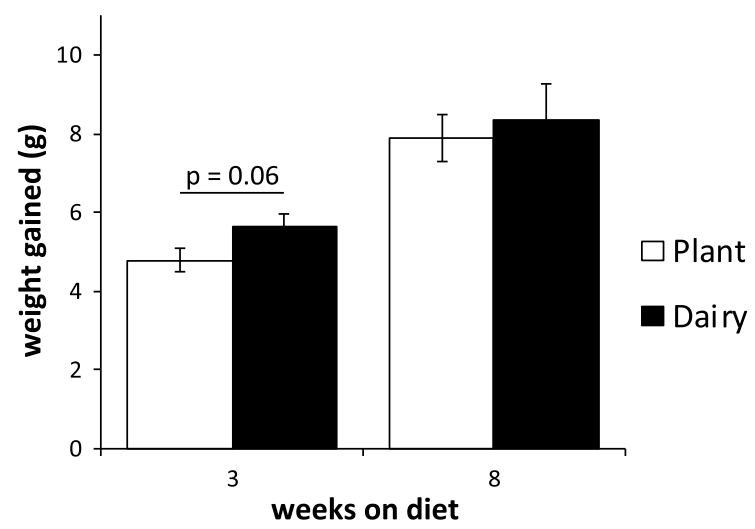

$\square$ Plant

Dairy
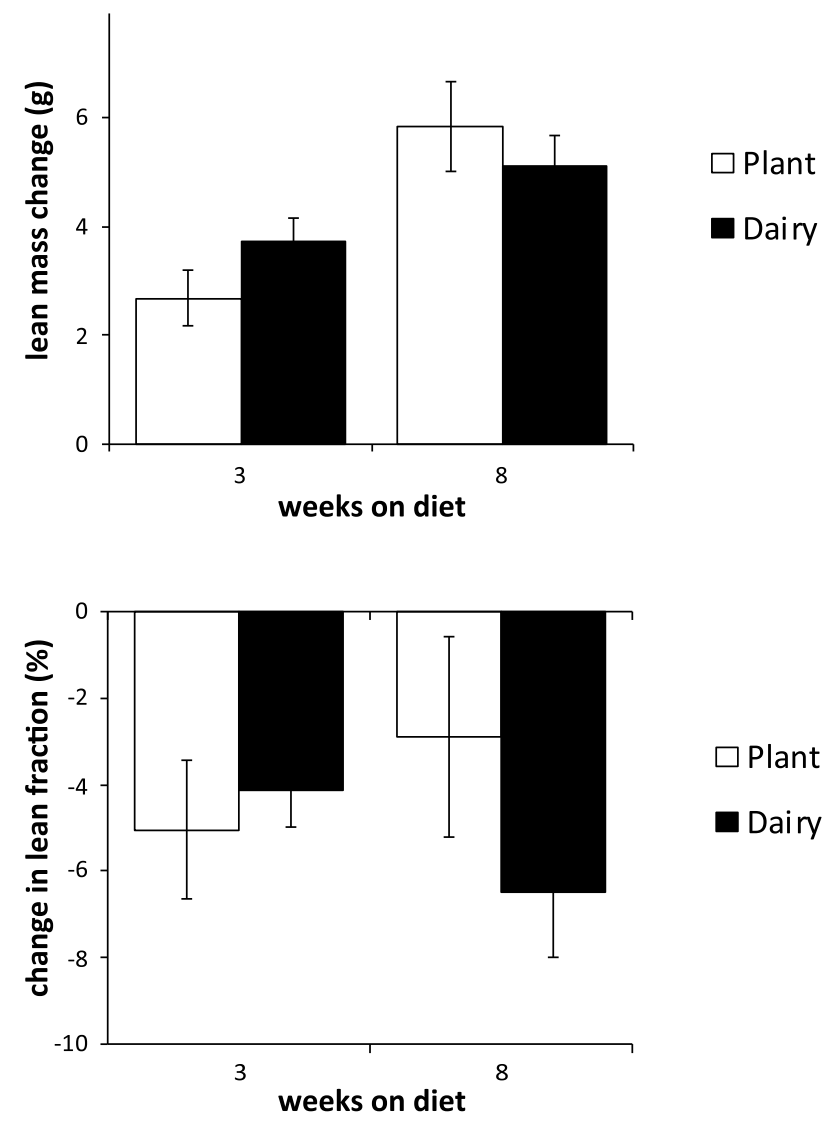

Fig. 2. Mice consuming plant or dairy protein diets have similar food consumption, weight gain, and body composition. (A) Food consumption was measured after 2 weeks on either diet. (B) Weight was determined immediately prior to diet start and after 3 and 8 weeks. (C-D) Fat and lean mass (C) and fat and lean fraction (D) were determined immediately prior to diet start and after 3 and 8 weeks. ( $n=9 /$ group; two-tailed $t$-test, $\left.{ }^{*}=p<0.05\right)$. Error bars represent SE. 


\section{Acknowledgments}

We would like to thank all the members of the Lamming and Fontana labs. The D.W.L. lab is supported in part by the NIH/National Institute on Aging (AG041765 and AG050135), a New Investigator Program Award from the Wisconsin Partnership Program, and a Glenn Foundation Award for Research in the Biological Mechanisms of Aging, as well as startup funds from the UW-Madison School of Medicine and Public Health and the UW-Madison Department of Medicine. This research was conducted while D.W.L. was an AFAR Research Grant recipient from the American Federation for Aging Research. The L.F. lab is supported by grants from the Bakewell Foundation and the Longer Life Foundation (an RGA/Washington University Partnership). This work was supported using facilities and resources from the William S. Middleton Memorial Veterans Hospital. This work does not represent the views of the Department of Veterans Affairs or the United States Government.

\section{References}

[1] Fontana L, Cummings NE, Arriola Apelo SI, Neuman JC, Kasza I, Schmidt BA, et al. Decreased consumption of branched-chain amino acids improves metabolic health. Cell Reports. 2016;16(2):520-30.

[2] Sluijs I, Beulens JW, van der AD, Spijkerman AM, Grobbee DE, van der Schouw YT. Dietary intake of total, animal, and vegetable protein and risk of type 2 diabetes in the European Prospective Investigation into Cancer and Nutrition (EPIC)NL study. Diabetes Care. 2010;33(1):43-8.

[3] Lagiou P, Sandin S, Weiderpass E, Lagiou A, Mucci L, Trichopoulos D, et al. Low carbohydrate-high protein diet and mortality in a cohort of Swedish women. J Intern Med. 2007;261(4):366-74.

[4] Levine ME, Suarez JA, Brandhorst S, Balasubramanian P, Cheng CW, Madia F, et al. Low protein intake is associated with a major reduction in IGF-1, cancer, and overall mortality in the 65 and younger but not older population. Cell Metab. 2014;19(3):407-17.

[5] Laeger T, Henagan TM, Albarado DC, Redman LM, Bray GA, Noland RC, et al. FGF21 is an endocrine signal of protein restriction. J Clin Invest. 2014;124(9):3913-22.

[6] Solon-Biet SM, McMahon AC, Ballard JW, Ruohonen K, Wu LE, Cogger VC, et al. The ratio of macronutrients, not caloric intake, dictates cardiometabolic health, aging, and longevity in ad libitum-fed mice. Cell Metab. 2014;19(3):418-30.

[7] Solon-Biet SM, Mitchell SJ, Coogan SC, Cogger VC, Gokarn $\mathrm{R}, \mathrm{McMahon} \mathrm{AC}$, et al. Dietary protein to carbohydrate ratio and caloric restriction: Comparing metabolic outcomes in mice. Cell Reports. 2015;11(10):1529-34.

[8] Smith GI, Yoshino J, Kelly SC, Reeds DN, Okunade A, Patterson BW, et al. High-protein intake during weight loss therapy eliminates the weight-loss-induced improvement in insulin action in obese postmenopausal women. Cell Reports. 2016;17(3):849-61.

[9] Appleby PN, Key TJ. The long-term health of vegetarians and vegans. Proc Nutr Soc. 2016;75(3):287-93.

[10] Rizza W, Veronese N, Fontana L. What are the roles of calorie restriction and diet quality in promoting healthy longevity? Ageing Res Rev. 2014;13:38-45.

[11] Cummings NE, Lamming DW. Regulation of metabolic health and aging by nutrient-sensitive signaling pathways. Molecular and Cellular Endocrinology. 2016.

[12] Brown-Borg HM, Buffenstein R. Cutting back on the essentials: Can manipulating intake of specific amino acids modulate health and lifespan? Ageing Res Rev. 2016.

[13] Miller RA, Buehner G, Chang Y, Harper JM, Sigler R, SmithWheelock M. Methionine-deficient diet extends mouse lifespan, slows immune and lens aging, alters glucose, T4, IGF-I and insulin levels, and increases hepatocyte MIF levels and stress resistance. Aging Cell. 2005;4(3):119-25.

[14] Orentreich N, Matias JR, DeFelice A, Zimmerman JA. Low methionine ingestion by rats extends life span. The Journal of Nutrition. 1993;123(2):269-74.

[15] Sucher S, Markova M, Hornemann S, Pivovarova O, Rudovich N, Thomann R, et al. A comparison of the effects of diets high in animal or plant protein on metabolic and cardiovascular markers in type 2 diabetes - a randomized clinical trial. Diabetes Obes Metab. 2017.

[16] Wheeler ML, Fineberg SE, Fineberg NS, Gibson RG, Hackward LL. Animal versus plant protein meals in individuals with type 2 diabetes and microalbuminuria: Effects on renal, glycemic, and lipid parameters. Diabetes Care. 2002;25(8):1277-82.

[17] Comerford KB, Pasin G. Emerging evidence for the importance of dietary protein source on glucoregulatory markers and type 2 diabetes: Different effects of dairy, meat, fish, egg, and plant protein foods. Nutrients. 2016;8(8):pii:E446.

[18] Fontana L, Adelaiye RM, Rastelli AL, Miles KM, Ciamporcero E, Longo VD, et al. Dietary protein restriction inhibits tumor growth in human xenograft models. Oncotarget. 2013;4(12):2451-61.

[19] Levy JC, Matthews DR, Hermans MP. Correct homeostasis model assessment (HOMA) evaluation uses the computer program. Diabetes Care. 1998;21(12):2191-2.

[20] Lamming DW, Ye L, Astle CM, Baur JA, Sabatini DM, Harrison DE. Young and old genetically heterogeneous HET3 mice on a rapamycin diet are glucose intolerant but insulin sensitive. Aging Cell. 2013;12(4):712-8.

[21] Mather K. Surrogate measures of insulin resistance: Of rats, mice, and men. Am J Physiol Endocrinol Metab. 2009;296(2):E398-9.

[22] Holmes AJ, Chew YV, Colakoglu F, Cliff JB, Klaassens $\mathrm{E}, \mathrm{Read} \mathrm{MN}$, et al. Diet-microbiome interactions in health are controlled by intestinal nitrogen source constraints. Cell Metab. 2017;25(1):140-51.

[23] Stone KP, Wanders D, Orgeron M, Cortez CC, Gettys TW. Mechanisms of increased in vivo insulin sensitivity by dietary methionine restriction in mice. Diabetes. 2014;63(11):372133.

[24] Orgeron ML, Stone KP, Wanders D, Cortez CC, Van NT, Gettys TW. The impact of dietary methionine restriction on biomarkers of metabolic health. Prog Mol Biol Transl Sci. 2014;121:351-76. 
[25] Wanders D, Forney LA, Stone KP, Burk DH, Pierse A, Gettys TW. FGF21 mediates the thermogenic and insulin-sensitizing effects of dietary methionine restriction but not its effects on hepatic lipid metabolism. Diabetes. 2017;66(4):858-67.

[26] Newgard CB, An J, Bain JR, Muehlbauer MJ, Stevens $\mathrm{RD}$, Lien LF, et al. A branched-chain amino acid-related metabolic signature that differentiates obese and lean humans and contributes to insulin resistance. Cell Metab. 2009;9(4):311-26.

[27] White PJ, Lapworth AL, An J, Wang L, McGarrah RW, Stevens RD, et al. Branched-chain amino acid restriction in Zucker-fatty rats improves muscle insulin sensitivity by enhancing efficiency of fatty acid oxidation and acyl-glycine export. Molecular Metabolism. 2016;5(7):538-51.
[28] Gojda J, Rossmeislova L, Strakova R, Tumova J, Elkalaf M, Jacek M, et al. Chronic dietary exposure to branched chain amino acids impairs glucose disposal in vegans but not in omnivores. Eur J Clin Nutr. 2017.

[29] Xiao F, Huang Z, Li H, Yu J, Wang C, Chen S, et al. Leucine deprivation increases hepatic insulin sensitivity via GCN2/mTOR/S6K1 and AMPK pathways. Diabetes. 2011;60(3):746-56.

[30] Xiao F, Yu J, Guo Y, Deng J, Li K, Du Y, et al. Effects of individual branched-chain amino acids deprivation on insulin sensitivity and glucose metabolism in mice. Metabolism. 2014;63(6):841-50. 